Q. Wang, et al., Int. J. Sus. Dev. Plann., Vol. 9, No. 1 (2014) 42-53

\title{
RELEASE BEHAVIOUR OF CRYPTOMERIA JAPONICA POLLEN ALLERGENIC CRY J 1 AND CRY J 2 IN RAINWATER CONTAINING AIR POLLUTANTS
}

\author{
Q. WANG ${ }^{1}$, S. NAKAMURA ${ }^{1}$, S. GONG ${ }^{1}$, M. SUZUKI ${ }^{1}$, D. NAKAJIMA ${ }^{2}$, Y. TAKAI ${ }^{1}$, S. LU $^{3}$, \\ K. SEKIGUCHI ${ }^{1} \&$ M. MIWA ${ }^{4}$ \\ ${ }^{1}$ Graduate School of Science and Engineering Saitama University, Japan. \\ ${ }^{2}$ National Institute for Environmental Studies, Japan. \\ ${ }^{3}$ Shanghai University, China. \\ ${ }^{4}$ Centre for Environmental Science in Saitama, Japan.
}

\begin{abstract}
Japanese cedar (Cryptomeria japonica) pollinosis is the most popular pollinosis in Japan. In recent years, it was reported that the most Cryptomeria japonica pollen allergenic species were scattered as fine particles in the urban atmosphere. It is thought that allergenic fine particles are responsible for inducing asthma by breaking into lower respiratory tract; this phenomenon was observed in field investigations during sunny days after rainfall. Hence, it is considered that the release of fine allergenic species derived from pollen grains may be induced during rainfall events. For this reason, we investigated the releasing behaviour of Cryptomeria japonica pollen allergenic species in rainwater containing air pollutants, through rainwater sampling and laboratory experiments. The pollen grain counts, pollen burst ratios, ionic concentrations and $\mathrm{pH}$ in each rainwater sample were measured, when rainwater samples were separately collected in Saitama City, a suburban area north of Tokyo metropolis. Additionally, three simulated rainwater (SR) samples were prepared to investigate the releasing behaviour of pollen allergenic species. In the samplings, the most pollen grains were trapped into initial rainwater (IR). Moreover, burst pollen grains were observed in many rainwater samples. Burst ratio of pollen grains were positively correlated with $\mathrm{pH}$ and ionic concentrations in rainwater. Therefore, it was thought that pollen grains were washed out by IR containing air pollutants. On the other hand, for the laboratory experiments, the elution of allergenic Cry j 1 and Cry j 2 was observed when pollen grains were exposed to different SR samples. A time-dependent increase of Cry $\mathrm{j} 1$ was observed, but the elution of Cry $\mathrm{j} 2$ was not observed from pollen grains exposed to SR samples. In particular, the elution of Cry j 1 increased by contact with SR samples under conditions of Asian dust events. The results demonstrated that the burst of pollen grains is associated with the production of fine particles containing pollen allergenic species, and that the release of allergenic species was induced by rainwater containing air pollutants. Keywords: Air-polluted precipitation, allergenic Cry $j$ 1, allergenic Cry j 2, Asian dust, crustal particles, Cryptomeria japonica pollen, releasing.
\end{abstract}

\section{INTRODUCTION}

Japanese cedar (Cryptomeria japonica) pollinosis has been increasing in Japan and currently affects over $26.5 \%$ of the population (even up to $40 \%$ in the urban areas of Tokyo) [1]. This pollinosis is caused by aspiration of the pollen grains from Cryptomeria japonica trees, which are evergreen needle-leaved trees containing wind-pollinated flower. These trees had been afforested in the mountainous areas from 1946 to 1956 for post-war lumber demand. However, the areas of forest have not been increased since the 1980s [2], and the areas of forest of these trees have become the largest area in artificial plantation currently [3]. Meanwhile, these trees were uncommon in urban areas in Kanto, Japan. Thus, the most airborne Cryptomeria japonica pollen grains in Kanto urban area are transported from mountain areas, several hundred kilometres away [4]. Worsening of pollinosis symptoms is induced by introducing allergenic species that coexist with air pollutants such as gases [5,6], polycyclic aromatic hydrocarbons (PAHs) [7], metallic particles [8,9] carbon aggregates [10], and known adjuvants [11]. It was also reported that small-sized pollen allergenic species adhere to carbon aggregates from vehicle emissions scattered in the atmosphere [12].

(C) 2014 WIT Press, www.witpress.com

ISSN: 1743-7601 (paper format), ISSN: 1743-761X (online), http://journals.witpress.com

DOI: 10.2495/SDP-V9-N1-42-53 
Cryptomeria japonica pollen has two main allergenic species, Cry j 1 and Cry j 2, which are responsible for pollinosis. Allergenic Cry $\mathrm{j} 1$ exists in the pollen wall and ubisch bodies on its original pollen surface, while allergenic Cry $\mathrm{j} 2$ is present as starch granules on the pollen grains [13]. According to the previous airborne sampling results, Cryptomeria japonica pollen allergenic species distribute abundantly in the size range below $1.1 \mu \mathrm{m}\left(\mathrm{PM}_{1.1}\right)$ [14]. It can be explained that these allergenic species are in the form of small-sized particles and can be released from coarse particles originated by Cryptomeria japonica pollen grains (about $30 \mu \mathrm{m}$ ) to fine allergenic particles in $\mathrm{PM}_{1.1}$. Therefore, these can be called daughter allergenic particles of Cryptomeria japonica pollen grains. It is thought that those daughter allergenic particles are responsible for inducing asthma by breaking into the lower respiratory tract. Actually, it is reported that symptoms of asthma patients were worsening during Cryptomeria japonica scattering season [15]. Especially, symptoms were notably worsened at sunny days after rainfall [16], with increasing fine allergenic Cry j 1 species in $\mathrm{PM}_{1.1}[17]$.

In addition, allergenic species released from Cryptomeria japonica pollen are easier to be adsorbed onto hydrophobic surfaces rather than hydrophilic surfaces [18]. Thus, it was possible that allergenic species were simultaneously adsorbed on PAHs and carbon aggregates trapped into rainwater. In a rain event, suspended particulate matter and gaseous substances are trapped into rainwater, which finally reaches the ground. Therefore, the ionic concentrations and $\mathrm{pH}$ in rainwater change due to the decrease in the air pollutants concentrations during rainfall. In particular, because most air pollutants are trapped into initial rainwater (IR), ionic concentrations and $\mathrm{pH}$ in subsequent rainwater changes continuously. On the other hand, there is the long-range transportation of Asian dust (AD) particles from the East Asian continent during the pollen scattering season in Japan by westerly winds, following global warming in recent years. When $\mathrm{AD}$ particles are transported into Japan, $\mathrm{pH}$ and ionic concentrations in rainwater increase drastically [19]. Hence, it was thought that air pollutants have not only a direct effect by synergically worsening pollinosis symptoms but also have an indirect effect by increasing the eluted concentrations of allergenic species because they can change the rainwater conditions. Actually, it was reported that elution of Cry j 1 was induced by solutions with high ionic concentrations [18], although those results were obtained under conditions above the upward range of pollutants concentration in rainfall in the atmosphere. The elution of Cryptomeria japonica pollen and its allergenic species in the presence of ionic concentrations and $\mathrm{pH}$ values observed in atmospheric rainwater has not been previously studied. Therefore, it is necessary to clarify the release mechanism of the pollen allergenic species under air pollutants influence. In this study, we investigated the behaviour of Cryptomeria japonica pollen grains and its allergenic species in rainwater as one of the environmental factors contributing to small-sized pollen allergenic species. In this paper, more experimental data were added, which deepened the debate on contents of the conference paper published on air pollution in 2012 [20].

\section{MATERIALS AND METHODS}

\subsection{Field investigation of Cryptomeria japonica pollen grains in the atmosphere}

2.1.1 Measurement of airborne pollen grains and sampling procedure for rainwater in urban area Rainwater was collected in Saitama University, located in the Kanto urban area, Japan (35.86422, 139.607870). The forests of Cryptomeria japonica are around the mountainous areas of Chichibu and neighbouring prefectures, several hundred kilometres away from the sampling site. Thus, Cryptomeria japonica pollen grains were transported from those circumjacent mountainous areas. According to the officially reported data from the Ministry of Environment, the scattering of AD in 
the Kanto area was observed with an annual average of three times, from 2001 to 2010, during pollen scattering spring season from February to April. The information about scattering of AD at Kanto area was referenced from the governmental web site of the Ministry of Environment [21]. The days of observation of $\mathrm{AD}$ at the monitoring site at Tsukuba city were defined as the scattering days of $\mathrm{AD}$ at the sampling site. Other meteorological data (precipitation, wind speed, wind direction and temperature) were obtained from the Saitama Institute of Public Health and the Okubo purification plant, located about $1.0 \mathrm{~km}$ from the sampling site.

Pollen grain counts were measured with a real-time pollen monitor (Model KH3000-01, Yamatronics Co., Ltd., Japan) operated at a flow rate $4.1 \mathrm{~L} / \mathrm{min}$. This device is able to distinguish airborne particles using optical system of forward and side scatter by a laser diode [22]. Moreover, this pollen monitor highly correlated with a Burkard sampler [23]. Rainwater was collected with a 'rain-go-round' rainwater sampler (Horiba, Co., Ltd.), which can partially collect rainwater from the $1 \mathrm{st}$ to the 7 th $\mathrm{mm}$ of rainwater, collecting $5 \mathrm{~mL}$ per each $\mathrm{mm}$ of rainwater on every event. In addition, this sampler is equipped with a cap that automatically opens when rain starts, then, the penetration of dry deposition in collected rainwater was minimised. The sampling site was carefully chosen in order to block the interference of raindrops from the roof of buildings or trees. The sampling period was from early March to the end of April 2010 during Cryptomeria japonica pollen scattering season. The collected rainwater samples were respectively put in micro tubes and centrifugally separated at 6,000 rpm for $10 \mathrm{~min}$. Then, the supernatants were set in a polyethylene bottle. Supernatants and residues were stored at $4^{\circ} \mathrm{C}$ until analysis.

2.1.2 Measurement of trapping pollen counts and ionic contents in rainwater

Burst of pollen grains in the residue was counted separately from non-burst pollen grains by the following procedure: the residue was put on a glass slide, and then dried at $37^{\circ} \mathrm{C}$ overnight. Then, pollen grains were dyed by Phöbus Blackly distain solution prepared with $0.6 \mathrm{mg}$ of methyl violet 2B, $30 \mathrm{~mL}$ of phenol, $180 \mathrm{~mL}$ of glycerin and $90 \mathrm{~mL}$ of ultrapure water [24]. Moreover, dyed pollen grains were counted by using an optical microscope (Shimadzu Co., Ltd., Japan) under 150 magnifications. Pollen grains on each slide were counted twice. Finally, average and standard deviation were calculated. Concentrations of ionic species and $\mathrm{pH}$ in rainwater were measured from the supernatants. The $\mathrm{pH}$ was measured with a $\mathrm{pH}$ meter (Model B-212, Horiba Co., Ltd., Japan). Ionic concentrations such as $\mathrm{Cl}^{-}, \mathrm{NO}_{3}^{-}, \mathrm{SO}_{4}{ }^{2-}, \mathrm{Ca}^{2+}, \mathrm{Na}^{+}, \mathrm{Mg}^{+}$and $\mathrm{NH}_{4}^{+}$were measured by ion chromatography (Model DX-100, Dionex Co., Ltd., Japan).

2.2 Laboratory experiments for investigation of the releasing behaviour of Cryptomeria japonica pollen allergenic species when exposed to three simulated rainwater (SR) samples

In order to investigate the releasing behaviour of Cry $\mathrm{j} 1$ and Cry $\mathrm{j} 2$ from Cryptomeria japonica pollen grains, three SR samples were prepared by changing the $\mathrm{pH}$ and ionic concentrations in different solutions (Table 1) in reference to the sampling results and data reported by other researchers $[19,25]$. IR samples were used, because pollen grains were abundantly trapped into initial rainfall. SR samples were used as those with the $\mathrm{pH}$ and ionic concentrations determined during the field sampling season in Saitama, Japan. IR samples when AD event was observed (IR-AD) were used, because $\mathrm{pH}$ and ionic concentrations in rainwater increased considerably due to trapped $\mathrm{AD}$ in it.

The releasing behaviour of Cry j 1 and Cry j 2 from pollen grains was measured in the different rainwater samples. The experiments were performed by the following method: $200 \mathrm{mg}$ of fresh pollen grains, collected by Japan Forest Tree Breeding Association, and $1 \mathrm{~mL}$ of each SR sample were mixed in a micro tube and stored in $4^{\circ} \mathrm{C}$ for $15,60,180,360,760$ and 1,440 min. After that time 
Table 1: $\mathrm{pH}$ and ionic concentrations of simulated rainwater samples.

\begin{tabular}{lrrrrrrrrrrrr}
\hline \multirow{2}{*}{$\begin{array}{l}\text { Rainwater } \\
\text { samples* }\end{array}$} & $\mathrm{pH}$ & $\mathrm{H}^{+}$ & $\mathrm{NH}_{4}{ }^{+}$ & $\mathrm{Ca}^{2+}$ & $\mathrm{Mg}^{2+}$ & $\mathrm{K}^{+}$ & $\mathrm{Na}^{+}$ & $\mathrm{SO}_{4}{ }^{2-}$ & $\mathrm{NO}_{3}{ }^{-}$ & $\mathrm{Cl}^{-}$ & $\mathrm{CO}_{3}{ }^{2-}$ & $\mathrm{Sum}$ \\
\hline IR & 4.24 & 60 & 135 & 60 & 25 & 5 & 85 & 140 & 130 & 100 & 0 & 740 \\
SR & 4.85 & 20 & 30 & 10 & 0 & 0 & 10 & 40 & 30 & 20 & 0 & 160 \\
IR-AD & 7.85 & 0 & 200 & 300 & 50 & 10 & 100 & 250 & 210 & 200 & 50 & 1,370 \\
\hline
\end{tabular}

*IR: initial rainwater samples; SR: simulated rainwater samples; and IR-AD: rainwater samples when $\mathrm{AD}$ event was observed.

the micro tubes were centrifuged at 14,800 rpm for $10 \mathrm{~min}$ and the supernatants were pipetted. The supernatants were solvent exchanged for buffer solution (Hepes buffered saline with EDTA and surfactant P20 (HBS-EP, GE Healthcare Co., Ltd., Japan): $10 \mathrm{mM}$ Hepes, $150 \mathrm{mM} \mathrm{NaCl}, 3 \mathrm{mM}$ EDTA, 0.005\% Surfactant P20) by the centrifugal filter units (Amicon Ultra-0.5, Millipore Co., Ltd., Japan). Solvent exchange was carried out according to the instructions of the centrifugal filter units. $500 \mu \mathrm{L}$ of supernatants were added in the filter device of Amicon Ultra-0.5. Subsequently, these were centrifugally separated at $14,800 \mathrm{rpm}$ for $15 \mathrm{~min}$. To recover the concentrated supernatants, the Amicon Ultra filter device was put upside down in a clean micro tube and then centrifuged at $4,000 \mathrm{rpm}$ for $2 \mathrm{~min}$ in order to transfer the concentrated supernatants from the device to the tube. Concentrated supernatants were diluted by HBS-EP to a volume of $500 \mu \mathrm{L}$ of solution. Finally, allergenic concentrations were measured by a Biacore J system (GE Healthcare Co., Ltd., Japan) based on the surface plasmon resonance (SPR) method. The SPR method was used to detect Cry j 1 and Cry j 2 concentrations by using allergen-specific monoclonal antibodies and the Biacore $\mathrm{J}$ system, as previously described [26] with the following minor modifications: Allergenic Cry $\mathrm{j} 1$ or Cry j 2 concentrations in measured samples were investigated based on Cry j 1 monoclonal antibody (MAb) (clone: 013, Asahi Food \& Healthcare Co., Ltd., Japan) or Cry j 2 MAb (clone: T27, Asahi Food \& Healthcare Co., Ltd., Japan) immobilised on a CM5 sensor chip (GE Healthcare Co., Ltd., Japan) by using the SPR method with the Biacore J system. Approximately $700 \mu \mathrm{g}$ of Cry j $1 \mathrm{MAb}$ or Cry j $2 \mathrm{MAb}$ were immobilised on the chip. The regeneration and dissociation of antigen-antibody complex reaction on the CM5 sensor chip were performed by $70 \mu \mathrm{L}$ of pH 2.0 glycine- $\mathrm{HCl}$ (GE Healthcare Co., Ltd., Japan). Finally, the results were converted into the concentrations of the allergenic Cry j 1 and Cry j 2 eluted from $1.00 \mathrm{mg}$ pollen grains (ng/mg) in mass.

\section{RESULTS AND DISSCUSSIONS}

\subsection{The airborne pollen results based on the field experiments}

\subsubsection{Daily variation of airborne pollen grains and meteorological conditions}

Figure 1 shows the daily variation of airborne pollen counts, wind direction, precipitation, temperature and wind speed during the 2010 spring season. Peaks of airborne pollen grains appeared in 17 March and 21 March under higher wind speed and temperature than the previous day. Similarly, the peak of 1 April appeared under high temperature. There was no correlation between airborne pollen counts and wind direction. Correlation between airborne pollen counts and temperature has been reported [27]. Moreover, it was also thought that airborne pollen counts were related to wind speed, because under 
stronger winds more pollen grains are released from the trees. Thus, airborne pollen counts in the urban area of Kanto Plain were affected by temperature and wind speed rather than wind direction. Airborne pollen grains were not observed on 24 and 25 March, because those days rained heavily all day long. However, during rainfall events on 16 and 21 March, airborne pollen grains did not decrease. With these observations, rainfall seemed to decrease pollen grains scattering only during the night. In addition, scattering of $\mathrm{AD}$ was observed in the Kanto area from midnight of 20 March to morning of 21 March, and then, it rained $1 \mathrm{~mm}$ of rainfall. Therefore, it was thought that $\mathrm{AD}$ was trapped into 21 March rainwater.
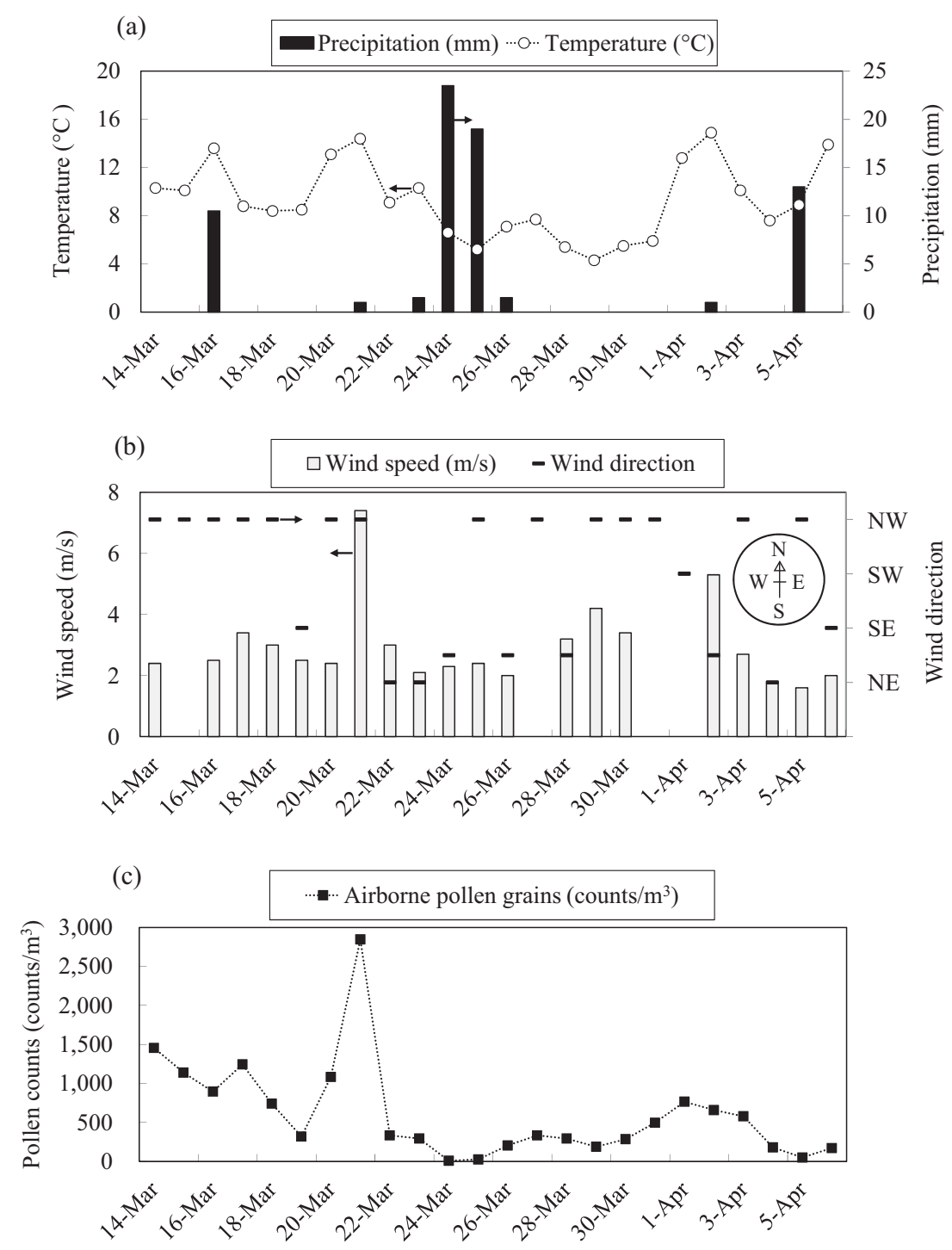

Figure 1: Time variation of (a) temperature, precipitation, (b) wind direction, wind speed and (c) airborne pollen counts during the pollen scattering spring seasons in 2010. Meteorological data was got from the Saitama Institute of Public Health and the Okubo water purification plant. 
3.1.2 Counting the number of pollen grains trapped into rainwater

During the spring period, rainwater samples were collected four times on 16 March $(10.5 \mathrm{~mm})$, 21 March $(1.0 \mathrm{~mm}), 24$ March $(24 \mathrm{~mm})$ and 5 April $(13 \mathrm{~mm})$, respectively. Table 2 indicates the variation of pollen counts collected by every $1.0 \mathrm{~mm}$ of rainwater after each rainfall event. Additionally, Fig. 2 indicates the collected ratio of pollen grains in every $1.0 \mathrm{~mm}$ of rainfall during each rainfall event, normalised to the initial value $(100 \%)$; therefore, the $1.0 \mathrm{~mm}$ rainfall on $21 \mathrm{March}$, could not be shown in Fig. 2. The highest standard deviation of pollen counts in rainwater was 14\%. Most pollen grains were trapped into initial rainfall, with exception of 5 April when pollen grains were trapped into the second $1.0 \mathrm{~mm}$ of rainfall rather than the first $1.0 \mathrm{~mm}$. On this day, initial rainfall was light rain, $0.5 \mathrm{~mm} / \mathrm{h}$, then, airborne pollen grains could not be completely trapped into the initial rainfall. From this result, it was demonstrated that most Cryptomeria japonica pollen grains were trapped into initial rainfall. Other authors have also reported that Cryptomeria japonica pollen grains were trapped into initial rainfall [28].

\subsubsection{Ionic concentrations in different rainfall events}

Ionic concentrations decreased with subsequent precipitation in the same rainfall event (Fig. 3). 24 March and 5 April had two rainfall events, hence as it can be seen in Fig. 3, in the second rainfall event, ionic concentrations increased again but decreased in subsequent $1.0 \mathrm{~mm}$ of rainfall. AD was observed on 20 March 2010 (Japan). Thus, AD particles were trapped into rainfall the next day. As a result, ionic concentrations became higher than rainfall in the

Table 2: The variation of pollen counts collected in every $1.0 \mathrm{~mm}$ of rainwater after each event during the pollen scattering spring season in 2010 (here, n.d means not detection).

\begin{tabular}{lccccccc}
\hline & \multicolumn{7}{c}{ Rainfall $(\mathrm{mm})$} \\
\cline { 2 - 8 } Sampling data & 1 & 2 & 3 & 4 & 5 & 6 & 7 \\
\hline 16 Mar. & $307 \pm 31$ & $29 \pm 1$ & $9 \pm 0$ & $2 \pm 0$ & $8 \pm 0$ & $3 \pm 0$ & $3 \pm 0$ \\
21 Mar. & $18 \pm 2$ & n.d. & n.d. & n.d. & n.d. & n.d. & n.d. \\
24 Mar. & $34 \pm 2$ & $7 \pm 0$ & n.d. & $5 \pm 0$ & $3 \pm 0$ & $8 \pm 0$ & $6 \pm 0$ \\
5 Apr. & $271 \pm 27$ & $356 \pm 46$ & $101 \pm 14$ & $13 \pm 0$ & $10 \pm 0$ & $6 \pm 0$ & $2 \pm 0$ \\
\hline
\end{tabular}

$*$ Average \pm standard deviation.

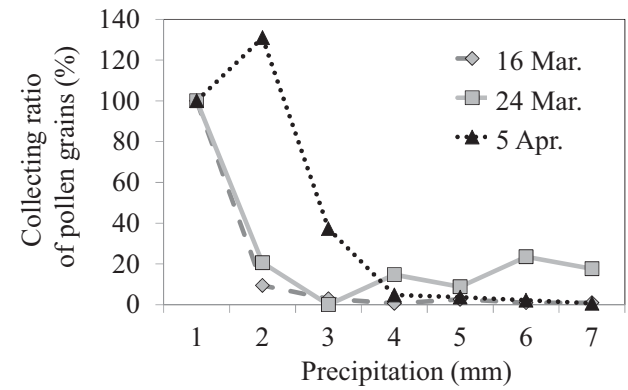

Figure 2: Collecting ratio of pollen grains in every $1.0 \mathrm{~mm}$ of rainfall during each rain event in 2010, normalized to the initial value (100\%). 

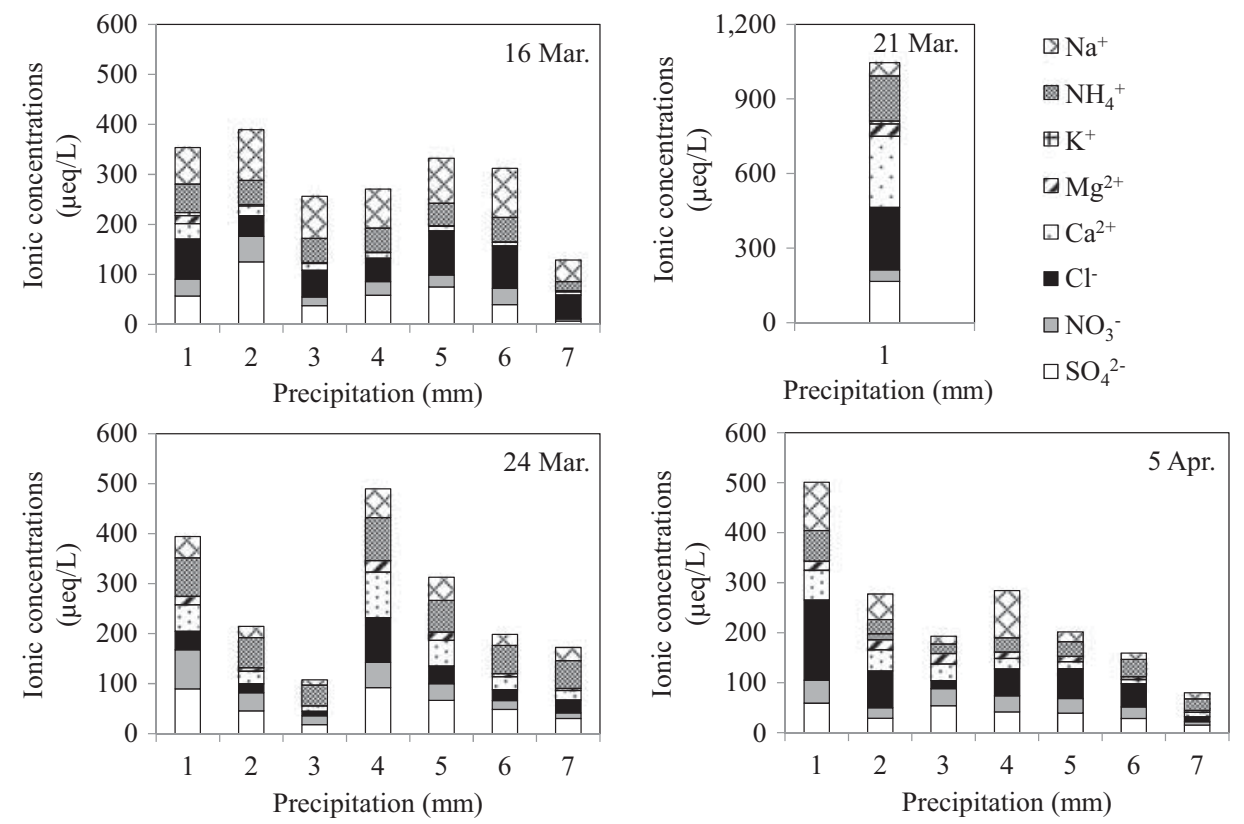

Figure 3: Ionic concentrations in different rain events. Rainwater samples were collected during 2010 spring season.

previous days before $\mathrm{AD}$ events. In particular, mineral ions such as $\mathrm{Ca}^{2+}$ derived from $\mathrm{AD}$ and/ or road dust increased about 2.5 times. In a previous report [29], elution concentration of Cry $\mathrm{j} 1$ was reported to increase when exposed to solutions with high ionic concentrations under weak basic conditions. Thus, these data suggest that the release of allergenic species was enhanced by the increase in ionic concentrations when the rainfall traps $\mathrm{Ca}^{2+}$-rich road dust and AD particles.

\subsubsection{Influence of $\mathrm{pH}$ and ionic concentrations on burst of the pollen grains trapped into rainwater samples}

Since elution of Cry j 2 is induced by the burst of pollen grains in contact with basic solutions [30], it was thought that releasing of Cry $\mathrm{j} 2$ is strongly dependent on solution $\mathrm{pH}$. In this section, we investigated the dependence on $\mathrm{pH}$ and the burst ratio of pollen grains. In addition, ionic concentrations were also investigated. Figure 4 shows examples of morphological change of Cryptomeria japonica pollen grain, in which Cryptomeria japonica pollen burst in rainwater samples. Figure 5 shows the correlation between burst ratio of pollen grains and $\mathrm{pH}$ and ionic concentrations in rainwater. Outliers were eliminated under the Smirnov-Grubbs test. The data of third millimetre of rainwater on 24 March was eliminated, because there were no pollen grains trapped in that rain sample. From these results, we can observe that despite a good correlation $(R=0.61, p<0.001)$, the burst ratio of pollen grains was only $30 \%$ in weakly basic rainwater. Therefore, it was thought that the burst of pollen grains might be also induced by other influential factors. On the other hand, correlation between the burst ratio of pollen grains and ionic concentrations was also observed, although at a lower significance level, compared to that of $\mathrm{pH}(R=0.52, p<0.05)$. 

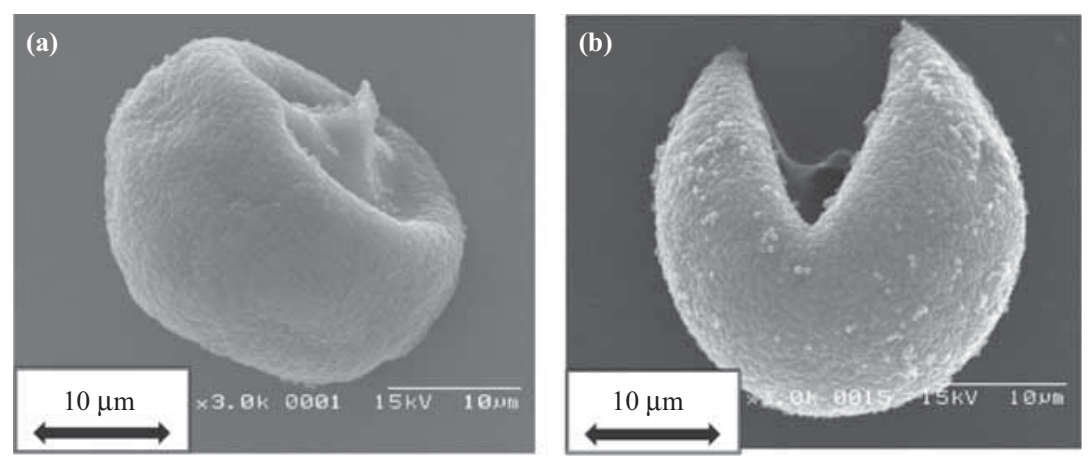

Figure 4: Examples of morphological behaviour of Cryptomeria japonica pollen grain. (a) non-burst pollen grain and (b) burst pollen grain. *Pictures taken with a scanning electron microscope.
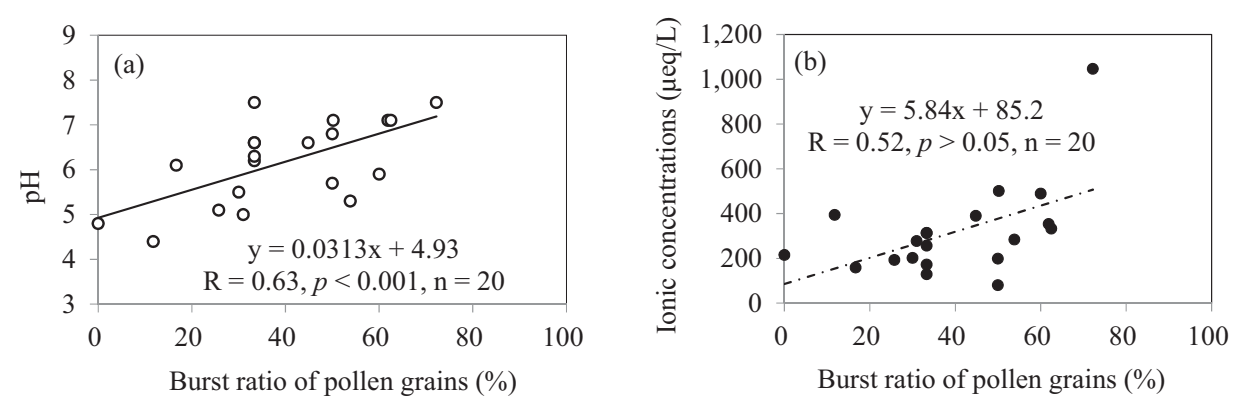

Figure 5: Correlation of (a) $\mathrm{pH}$ and (b) ionic concentration and burst ratios of pollen grains in rainwater. Outlier was eliminated by the Smirnov-Grubbs test.

Scattering of AD was observed at the night time on 20 March, and the samples indicated that AD was trapped into rainfall on 21 March. Most pollen grains were burst in rainwater on 21 March. Rainfall trapping AD was reported to increase $\mathrm{pH}$ above 7.0 [19], moreover, $\mathrm{pH}$ in rainwater on 21 March also increased. From this result, it was observed that the burst ratio of pollen increased with increasing $\mathrm{pH}$ and ionic concentrations. Therefore, it is possible that rainfall trapping AD is one of the important factors that affects the release the pollen allergenic species of Cry $\mathrm{j} 1$ and Cry $\mathrm{j} 2$. Two major daughter allergenic species were released from pollen grains, which may be re-suspended as fine particles containing allergenic species.

\subsection{Laboratory experiment results of releasing behaviour of allergenic species from Cryptomeria} japonica pollens when contacted with SR samples

Figure 6 shows the time variation of eluted Cry j 1 and Cry j 2 concentrations when in contact with three SR samples. Elution of Cry j 1 was observed in IR-AD, IR and SR in increasing order. Cry j 2 was also observed in these SR samples. However, increasing elution of Cry j 2 with time in contact was not observed. It was reported that elution of Cry $\mathrm{j} 1$ was induced by solutions with high ionic concentration, those results were obtained under conditions above the upward range of pollutants concentration in the atmosphere [18]. The elution rates and concentrations of allergenic species 


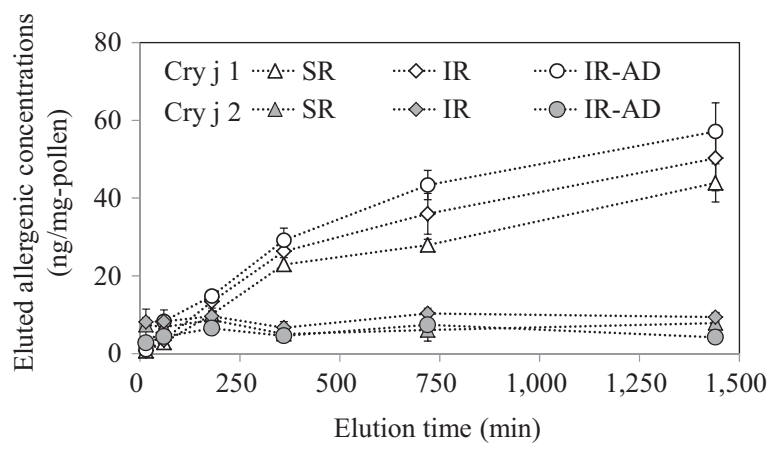

Figure 6: Time variations of eluted Cry j 1 and Cry j 2 concentrations from pollen grains in SR, IR and IR-AD solutions $(n=3)$.

increased with higher $\mathrm{pH}$ and ionic concentrations in rainwater. Ionic concentrations in subsequent rainwater that trapped pollen grains and deposited them decreased with subsequent precipitation; moreover, the elution of allergenic species decreased gradually. Hence, it can be thought that $\mathrm{pH}$ and ionic concentrations in initial rainfall are important factors affecting the elution rates of daughter allergenic species derived from Cryptomeria japonica pollens.

Based on the report that the amount of Cry j 1 in pollen grains is $435 \pm 169 \mathrm{ng} / \mathrm{mg}$ [31], it was estimated that the percentages of eluted Cry $\mathrm{j} 1$ are $13.1 \%$ in IR-AD, $11.6 \%$ in IR and $10.1 \%$ in SR, respectively. According to some reports of scattering counts of Cryptomeria japonica pollens in the urban area of Kanto Plain, Japan [14], the mass of each pollen grain [32] and the contents of Cry j 1 [31], it was estimated that the airborne concentrations of Cry j 1 eluted were 25.4, 22.9, $28.9 \mathrm{pg} / \mathrm{m}^{3}$ by IR, SR and IR-AD, respectively. It has been also reported that the symptoms of pollinosis appear when reaching a few $\mathrm{pg} / \mathrm{m}^{3}$ of Cryptomeria japonica pollen allergenic concentrations in the atmosphere [26]. Hence, the elution of daughter allergenic species induced when pollen is exposed to rainfall under a polluted atmosphere, especially $\mathrm{AD}$, and the subsequent re-suspension of these allergenic species may worsen asthmatic symptoms in sensitive population in urban areas.

\section{CONCLUSIONS}

In this study, we investigated the behaviour of Cryptomeria japonica pollen grains and its allergenic species during rainfall in the Saitama urban area, Japan. The results indicate that the most pollen grains are trapped into IR. Moreover, the burst ratio of pollen grains increases with increasing ionic concentrations and $\mathrm{pH}$ in rainwater, including the possibility of re-suspension of smaller pollen particles containing allergenic species after their morphological change. The laboratory results indicate that the three SR samples elute allergenic species. In particular, elution concentrations of allergenic species were enhanced by IR-AD. Hence, these results suggest that asthma derived from pollinosis may be enhanced after a rainfall event, especially after rainfall during AD events. Based on the evidences obtained in this study, it can be thought that daughter allergenic species are easily released during rainfall, and afterwards re-suspended as allergenic fine particles in the urban atmosphere during sunny days after a rainfall event. There have been reports about the elution behaviour of allergenic species; nevertheless, the simulated conditions on those experiments correspond with pollen grains after they are aspirated into the human respiratory tract. Then, their results cannot be extrapolated to the releasing behaviour in atmospheric rainwater. The results indicate that all SR samples are able to elute allergenic species above the threshold value that triggers asthma from 
pollinosis. Hence, it is thought that it is important to clarify the behaviour of airborne pollen grains and its allergenic species in atmospheric rainwater. Moreover, the results suggest that air pollutants have not only a direct effect by synergically worsening pollinosis symptoms but also have an indirect effect by increasing the eluted concentrations of allergenic species, since they can change the rainwater conditions.

\section{ACKNOWLEDGEMENT}

Some works of this study were supported by the Special Funds for Innovative Area Research (No. 20120015, FY 2008 FY2012) and Grant-in-Aid for Challenging Exploratory Research (No. 23651005, FY 2011 FY2012) of Japanese Ministry of Education, Culture, Sports, Science and Technology (MEXT), Japan.

\section{REFERENCES}

[1] Nishihata, S., Inoue, S., Saiga, T., Sahashi, N., Suzuki, S., Murayama, K., Yokoyama, T. \& Saito, Y., Prevalence rate of allergy to Japanese cedar pollen in Tokyo. Japanese Society of Allergology, 48(6), pp. 597-604, 1999 (in Japanese).

[2] Okuda, M., Usami, A. \& Kisikawa, R., Study of recent yearly trend of increase in airborne pollen of Japanese cedar and cypress pollen. The Japanese Society of Allergology, 55(12), pp. 1531-1535, 2006 (in Japanese).

[3] Forestry Agency, available at http://www.rinya.maff.go.jp/j/hozen/kafun/data.html (accessed 19 June 2012) (in Japanese).

[4] Kanazashi, T. \& Suzuki, M., The estimation of the pollen source areas of Cryptomeria japonica D. Don which have high contributions to the Japanese metropolitan region. The Japanese Forest Society, 92, pp. 298-303, 2010 (in Japanese).

[5] Bevelander, M., Mayette, J., Whittaker, L.A., Pavegio, S.A., Jones, C.C., Robbins, J., Hemenway, D., Akira, S., Uematsu, S. \& Poynter, M.E., Nitrogen dioxide promotes allergic sensitization to inhaled antigen. The Journal of Immunology, 179, pp. 3680-3688, 2007.

[6] Iijima, M.K. \& Kobayashi, T., Nasal allergy-like symptoms aggravated by Ozone exposure in a concentration-dependent manner in Guinea Pigs. Toxicology, 199, pp. 73-83, 2004. doi: http:// dx.doi.org/10.1016/j.tox.2004.01.008

[7] Kanoh, T., Suzuki, T., Ishimori, M., Ikeda, S., Ohasawa, M., Ohkuni, H. \& Tanetoshi, Y., Adjuvant activities of Pyrene, Anthracene, Fluoranthene and Benzo (a) Pyrene in production of anti-IgE antibody to Japanese cedar pollen allergen in mice. Journal of Clinical and Laboratory Immunology, 48, pp. 133-147, 1996.

[8] Paolucci, C., Ponti, J., Fabbri, M.V., Breda, D., Sabbioni, E. \& Burastero, S.E., Platinum group elements enhance the allergic immune response by acting on dendritic cells. International Archives of Allergy and Immunology, 143, pp. 225-236, 2007. doi: http://dx.doi. org/10.1159/000099466

[9] Lambert, A.L., Dong, W., Selgrade, M.J.K. \& Gilmour, M.I., Enhanced allergy sensitization by residual oil fly ash particles is mediated by soluble metal constituents. Toxycology and Applied Pharmacology, 165, pp. 84-93, 2000. doi: http://dx.doi.org/10.1006/taap.2000.8932

[10] Zijverden, M. \& Granum, B., Adjuvant activity of particulate pollutants in different mouse models. Toxicology, 152, pp. 69-77, 2000. doi: http://dx.doi.org/10.1016/S0300-483X(00)00293-6

[11] Maejima, K., Tamura, K., Nakajima, T., Taniguchi, Y., Saito, S. \& Takenaka, H., Effects of the inhalation of diesel exhaust, kanto loam dust or diesel exhaust without particles on immune responses in mice exposed to Japanese cedar (Cryptomeria japonica) pollen. Inhalation Toxicology, 13, pp. 1047-1063, 2001. doi: http://dx.doi.org/10.1080/089583701753210407 
[12] Namork, E., Johansen, B.V. \& Løvik, M., Detection of allergens adsorbed to ambient air particles collected in four European cities. Toxicology Letters, 165, pp. 71-78, 2006. doi: http://dx.doi.org/10.1016/j.toxlet.2006.01.016

[13] Nakamura, S., Sato, F. \& Nakamura, N., Immunocytochemical localization of cry j 1 and cry j 2 - the allergenic proteins of Japanese cedar pollen - in the germinated pollen. Japanese Journal of Palynology, 50(1), pp. 15-22, 2004 (in Japanese).

[14] Wang, Q., Kurihara, K., Kiryu, H., Sakamoto, K., Miwa, M. \& Uchiyama, I., Daily variation differences between airborne Japanese cedar pollen and its respirable allergen particulate matters during the most severe pollination seasons. Earozoru Kenkyu, 23, pp. 120-126, 2008 (in Japanese).

[15] Taylor, P.E. \& Jonsson, H., Thunderstorm asthma. Current Allergy and Asthma Reports, 4, pp. 409-413, 2004.

[16] Nakada, H., Nakagome, K., Takaku, Y., Nishihara, F., Yamaguchi, T., Soma, T., Hagiwara, K., Kanazawa, M., Kase, Y. \& Nagata, M., Questionnaire for determining relationship between nasal and asthma symptoms. Japanese Society of Allergology, 59(6), pp. 688-698, 2010 (in Japanese).

[17] Wang, Q., Nakamura, S., Lu, S., Nakajima, D., Suzuki, M., Sakamoto, K. \& Miwa, M., Release behavior of small sized daughter allergens from Cryptomeria japonica pollen grains during urban rainfall event. Aerobiologia, 28, pp. 71-81, 2012.

[18] Sagehashi, M., Fukuda, T., Fujii, T., Sakai, Y. \& Sakoda, A., Elution and adsorptive concentration of Japanese cedar (Cryptomeria japonica) pollen allergen in environmental water. Water Science and Technology, 52(9), pp. 37-43, 2005.

[19] Kawamura, C. \& Hara, H., Influence of Kosa in precipitation chemistry in Japan. Japan Society for Atmospheric Environment, 41(6), pp. 335-346, 2006 (in Japanese).

[20] Nakamura S., Wang Q., Gong S., Takai Y., Lu S., Nakajima D., Suzuki M., Sekiguchi K. \& Miwa M., Release rate of daughter allergenic species from Cryptomeria japonica pollen grains trapped in air polluted wet deposition. Air Pollution XX Ecology and the Environment, 157, pp. 387-398, 2012.

[21] Ministry of the Environment, available at http://www.env.go.jp/air/dss/past/index.html (accessed 19 June 2012) (in Japanese).

[22] Seno, S., Dake, Y., Sakoda, T., Saito, Y., Ikeda, H., Kitano, H., Kitajima, K. \& Enomoto, T., 2001 Survey of pollen in Wakayama city with real-time pollen counter. Nihon jibiinkoka gakkai kaiho, 105(3), pp. 232-239, 2002(in Japanese).

[23] Takahashi, Y., Kawashima, S., Fujita, T., Ito, C., Togashi, R. \& Takeda, H., Comparison between real-time pollen monitor KH-3000 and Burkard sampler. Japanese Journal of Allergology, 50(12), pp. 1136-1142, 2001(in Japanese).

[24] Ariga, R., Morphological Observation method for pollens become a cause of the pollinosis. Reports of Environmental Research and Control Center, 76, p. 128, 1993 (in Japanese).

[25] Saitama prefecture official website (last access: 19 June 2012), http://www.pref.saitama.lg.jp /uploaded/attachment/407386.pdf (in Japanese).

[26] Takahashi, Y., Ohashi, T., Nagoya, T., Sakaguchi, M. \& Yasueda, H., Possibility of real-time measurement of an airborne Cryptomeria japonica pollen allergen based on the principle of surface plasmon resonance. Aerobiologia, 17, pp. 313-318, 2001.

[27] Bartkova - Scevkova, J., The influence of temperature, relative humidity and rainfall on the occurrence of pollen allergens (Betula, Poaceae, Ambrosia artemisiifolia) in the atmosphere of Bratislava (Slovakia). International Journal of Biometeorology, 48, pp. 1-5, 2003.

[28] Saburi, Y., Yazawa, A., Sakurai, K., Hayashi, M. \& Sato, Y., Elimination of Japanese cedar (Cryptomeria japonica) aeropollen by rainfall. Japanese Society of Public Health, 39(10), pp. 809-815, 1992 (in Japanese). 
[29] Wang, Q., Nakamura, S., Gong, X., Lu, S., Nakajima, D., Wu, D., Suzuki, M., Sakamoto, K. \& Miwa, M., Evaluation of elution behavior and morphological change of Cryptomeria japonica pollen grain and release of its daughter allergenic particles by air polluted rainfall. Air Pollution XVIII, Ecology and the Environment, 136, pp. 185-197, 2010.

[30] Nohara, O., Imai, T., Endo, T., Saneyoshi, K., Ohmori, T., Saito, S., Taniguchi, Y., Fujimaki, H. \& Moriyama, H., Relationship between the morphological change of Japanese cedar (Cryptomeria japonica) pollen grains and the release of major allergens from the pollen. Japanese Society of Allergology, 46(12), pp. 1235-1242, 1997 (in Japanese).

[31] Fukuda, Y., Yasueda, H., Saito, A. \& Kondo, T., Investigation of the variation of cry j 2 concentration in pollen among Sugi (Cryptomeria japonica D. Don) trees using a newly established extraction method. Japanese Society of Allergology, 56(10), pp. 1262-1269, 2007 (in Japanese).

[32] Ohashi, E. \& Ooka, R., Indoor air-pollution by Japanese cedar pollen (2): Measurement of particle diameter and weight of cedar pollen, and its aerodynamic diameter. 2011 Conference on Architectural Institute of Japan, pp. 939-940, Tokyo, Japan, 2001 (in Japanese). 